\title{
HIGH-TEMPERATURE STEAM AND AIR OXIDATION OF CHROMIUM-COATED OPTIMIZED ZIRLOTM
}

\author{
Gauthier Bourdon $^{a, b, *}$, MARtin ŠEveČEK $^{a}$, JAKub KReJČí ${ }^{c, a}$, \\ LADISLAV CVRČEK ${ }^{d}$ \\ ${ }^{a}$ Czech Technical University in Prague, Faculty of Nuclear Sciences and Physical Engineering, Břehová 7, 115 \\ 19 Prague 1, Czech Republic \\ ${ }^{b}$ Grenoble-INP, Phelma, 3 Parvis Louis Néel, 38016 Grenoble, France \\ ${ }^{c}$ UJP PRAHA a.s., Nad Kaminkou 1345, 15610 Prague - Zbraslav, Czech Republic \\ ${ }^{d}$ Czech Technical University in Prague, Faculty of Mechanical Engineering, Technická 4, 16607 Prague 6, Czech \\ Republic \\ * corresponding author: gauthier.bourdon@grenoble-inp.org
}

\begin{abstract}
The presented study focuses on Cr-coated cladding material and its oxidation performance in high-temperature steam and air. As the substrate material, Optimized ZIRLO ${ }^{\mathrm{TM}}$ was used which was coated by chromium using unbalanced magnetron sputtering. The experimental methods are described and the presented results focus mainly on weight gain and oxidation kinetic evaluation. The experiments were carried out in the high-temperature range between 1000 and $1300{ }^{\circ} \mathrm{C}$. The test conditions focus mainly on the air oxidation tests that are relevant for some of severe accidents with air ingress and have not yet been studied in detail and are not available in literature. These data are supported with steam oxidation data to directly compare the kinetics in two different oxidizing environments.
\end{abstract}

KEYWORDS: Cladding material, accident tolerant fuel, steam oxidation, air oxidation.

\section{INTRODUCTION}

Since the Fukushima-Daiichi accident in 2011, new nuclear fuel and cladding materials have been investigated and developed to further enhance safety of currently operated Nuclear Power Plants. Generally, they are called Accident Tolerant or Advanced Technology Fuels. The main objective of these advanced materials is to enhance the accidental tolerance in case of design basis accidents (DBAs) and design extension conditions. As one of the ATF candidates, new coated cladding materials are being studied [1, 2]. The objectives of these new cladding materials include prevention of a degradation and failure of claddings due to excessive oxidation during postulated DBAs such as Loss of Coolant Accident (LOCA) or more severe ones with air ingress. Indeed, when there is an accident with air ingress in a reactor core, a spent fuel pool [3] or in transportation cask, cladding strongly oxidizes in air or steam/air mixture. This causes release of heat as well as acceleration of cladding degradation and progression of accident scenario. The application of protective coatings was proposed to protect the Zr-based alloys under high-temperature accidental conditions and to prevent breakaway oxidation. Many coating materials have been studied so far, but the most promising seems to be material coated with pure chromium or Cr-based materials.

Further development of these materials is motivated by the fact that although current alloys are very efficient in terms of oxidation at normal operating conditions and have good mechanical properties, during accidents as described above, they undergo a strong oxidation which results in degradation of their mechanical properties. In addition, there is a lack of high-quality experimental data on these new materials that will allow a comparison of their performance and also development of new correlations that can be implemented into simulation tools that are used for evaluation or licensing.

\section{MATERIALS}

\subsection{Substrate}

All of the tests presented in this paper were done either with uncoated as-received Optimized ZIRLO ${ }^{\mathrm{TM}}$ or Cr-coated Optimized ZIRLO ${ }^{\mathrm{TM}}$. This alloy has been developed by Westinghouse Electric Company and has been utilized in Light Water Reactors (LWRs) worldwide since 2000 and also in WWER reactors that are in operation in the Czech Republic. According to [4, the composition of Optimized ZIRLO ${ }^{\mathrm{TM}}$ with partially recrystallized annealed microstructure (pRXA) is shown in Table 1. All uncoated samples are $30 \mathrm{~mm}$ high cylinders with an outer diameter of $9.14 \mathrm{~mm}$ and inner diameter is $8 \mathrm{~mm}$. Two holes have been drilled in the top part of the sample in order to be able to hang them during the experiment. The hole diameter (HO) is about 2-3 mm (Figure 2). Mechanical properties of the substrate alloy are [4:

- $0.2 \%$ yield strength - 469-655 MPa

- minimum elongation - $12 \%$; expected about - $25 \%$

- contractile strain ratio between 1.5 and 2.25 
- texture in radial, hoop and axial directions $\approx 0.6$, 0.35 and 0.05

\begin{tabular}{lllll}
\hline Alloy & Micro. & Nb & Sn & Fe \\
\hline Optimized ZIRLO & pRXA & 1 & 0.67 & 0.1 \\
\hline
\end{tabular}

TABLE 1. Chemical composition of Optimized ZIRLO $^{\text {TM }}[\%]$

Other properties of Optimized ZIRLOTM used in design of experiments can be found in [5]. The transition of heat capacity of Optimized ZIRLO ${ }^{\mathrm{TM}}$ shown in Figure 1 shows expected transformation region from HCP alpha to mixed alpha+beta region and finally to BCC beta phase at high temperature. Some of the Optimized ZIRLO ${ }^{\text {TM }}$ properties are similar to Zircaloy4 such as thermal conductivity, coefficient of thermal expansion, elastic and shear modulus. The properties of the substrate are used for fuel performance modelling that is ongoing and will be published in the near future and for optimization of the deposition technique that slightly differs for different substrate alloys.

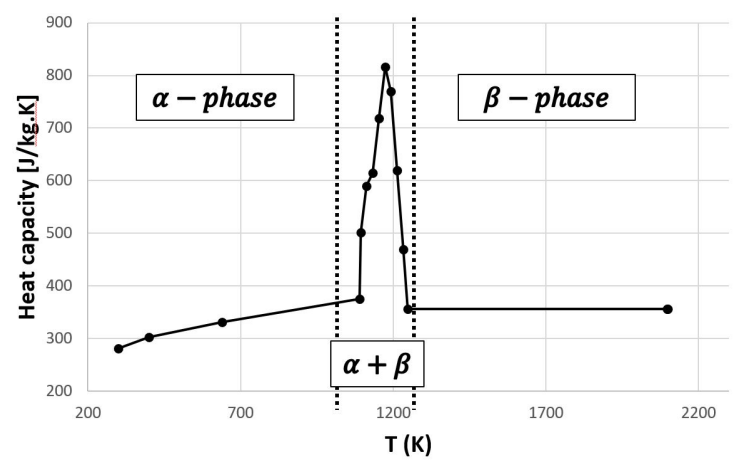

Figure 1. Heat capacity for Optimized ZIRLO ${ }^{\mathrm{TM}}$. These values are taken from Frapcon/Fraptran correlation, thus they are approximate.
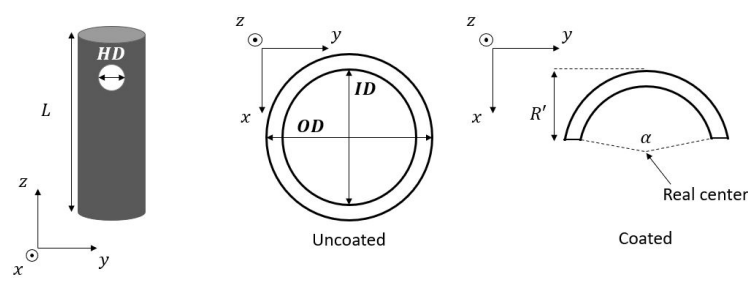

Figure 2. Schematics of two geometries of samples used. Uncoated samples have cylindrical geometry. Coated samples are almost half cylinder. R' is measured to determine the $\alpha$ parameter in order to calculate the accurate surface of coated samples.

\subsection{Coated Cladding}

The unbalanced magnetron sputtering method was chosen as the deposition technique of protective coating for the current study. It is considered as one of the Physical Vapor Deposition (PVD) methods that is able to produce high-quality relatively thick coatings at low temperature. However, it produces line-of-sight coatings which means that it cannot coat convex geometries such as internal diameter (ID) of the tubes used as cladding. The tubular cladding segments can be coated only on the outer surface but then the inner uncoated surface will strongly affect the results when testing oxidation resistance. Two approaches were chosen to neglect the effect of inner oxidation of uncoated material:

(1.) Welding of end plugs on both ends of the tubular segments and coating the whole sample including end caps and later use TIG welding for pressurization and sealing

(2.) Cutting the tubular samples into two halves and coating the whole sample surface including the ID

The first approach was presented in previous works [6. 7], the second approach was chosen in this study due to lower costs and time requirements. The sample geometry of both coated and uncoated samples is shown in Figure 2, It can be seen that tubular segments were machined first and cut into two halves before coating deposition.

\subsubsection{Magnetron SPuttering}

The coating was deposited using Magnetron Sputtering technology. This technique is based on depositing a thin layer of coating using gaseous plasma. Unbalanced magnetron sputtering has been chosen for the coating since it allows an improved control of the coating deposition process. In particular, this avoids an overly intense bombardment of the substrate by the ions of the placement, which could modify its physical properties. More information about similar techniques can be found in [8, 9]. The coating of the samples is carried inside the Hauzer Flexicoat 850 machine which is a semi-industrial commercial machine that has been modified in order to produce required coating properties suitable for nuclear cladding applications. The samples were first ultrasonically cleaned in acetone and dried with a blower. Then the surface of the samples was cleaned by ion etching in argon plasma for 20 minutes. This procedure removes the thin oxide layer and impurities from the samples. DC mode has been used with two cathodes of $\mathrm{Cr}(99.6 \%)$ powered to $6 \mathrm{~kW}$. The deposition has been done at $250^{\circ} \mathrm{C}$ and $0.2 \mathrm{~Pa}$ with a gas flow Argon at $90 \mathrm{sccm}$. Final coating consisted of ten chromium interlayers because every 70 minutes the deposition of the coating was interrupted for 60 minutes. During these nine interruptions, the temperature dropped to $100{ }^{\circ} \mathrm{C}$. The total thickness of the $\mathrm{Cr}$ coatings was measured with a Calotest instrument (CSM, Switzerland) and was found to be $18.6 \pm 0.1 \mu \mathrm{m}$. 


\section{EXPERIMENTAL}

There are several differences between air and steam oxidation of cladding materials in general. The oxidation in air leads to the early cracking of the protective $\mathrm{ZrO}_{2}$ oxide layer (breakaway) which leads to the formation of $\mathrm{ZrN}$ with a very porous structure that can be further reoxidized [10. Moreover, the oxidation of Zr-based alloys in air is usually faster than in steam. In steam at high temperature, the breakaway may be also observed but usually in later stages. Additionally, in steam there is a problem of hydrogen absorption in the cladding material, which degrades the cladding properties [11, 12]. Oxidation in steam occurs during DBAs such as LOCA [13, oxidation in air or steam/air mixture occurs during more severe accidents with air ingress such as accident in spent pool with a failed heat removal system [3].

\subsection{OxidATION IN AIR}

Each sample is held by a platinum wire at a known distance from the thermocouple. As it is impossible to place the thermocouple on the surface of the sample, it is placed as close as possible to the sample. Inside the furnace there is a $24 \mathrm{~mm}$ diameter quartz tube (item 21 in Figure 99, where the sample will be placed. The temperature profile was measured before the start of the experiment in order to determine the temperature of the sample during the experiment. It is assumed that the temperature profile will be the same once the specimen is placed inside the furnace.

The specimen is then placed outside the furnace (position 2 in Figure 9). The furnace and the glassware are subjected to a flow of Argon for 5 minutes to remove atmospheric gases, and then to a flow of Argon $\left(50\right.$ L.h $\left.{ }^{-1}\right)$ and synthetic Air $\left(100 ~ L . h^{-1}\right)$ for conditioning the furnace. The gases are mixed in the Controlled Evaporating System (CEM) from Bronkhorst used also at different institutes [14].

The specimen is later inserted into the preheated resistance furnace (position 1 in Figure 9p within predefined temperature zone $\left( \pm 6{ }^{\circ} \mathrm{C}\right)$ which is about $4-5 \mathrm{~cm}$ long. The flow of Argon and air remains constant. The temperature is recorded throughout the experiment. Once the specimen has reached the desired temperature $\pm 3^{\circ} \mathrm{C}$, the exposure time is measured. Once the desired exposure time has elapsed, the sample is placed outside the furnace and cooled with Argon at room temperature. Cooling the sample makes it possible to preserve the microstructure. The experiments were done at several temperature levels between 1000 and $1300^{\circ} \mathrm{C}$.

\subsection{Oxidation in Steam}

Same as for oxidation with air, the enclosure is first conditioned with Argon and then with a mixture of Argon (50L.h ${ }^{-1}$ ) and steam. The steam is obtained thanks to the CEM which is heated to $180{ }^{\circ} \mathrm{C}$. Water is incorporated in the CEM with a flow rate of 85 g.h $\mathrm{h}^{-1}$. A pump with a tank supplies a smaller tank in height (see elements 7,8,9 in Figure 9). The water level in the small tank must remain within a specific region to allow the flow-meter to operate properly. The pump is adjusted accordingly. The procedure is then the same as for oxidation with air, except for cooling. Here, water at $0{ }^{\circ} \mathrm{C}$ cooled with ice cubes is used to quench the specimen. It is more effective than cooling with Argon and also more prototypical for LOCA accident in which rapid quench is expected at the end of the transient. Because it is possible that cooling water may evaporate during the experiment and change the oxidation environment, this technique is not used for oxidation in air. At the end of the experiment, the specimen is placed inside an oven in order to dry it and to characterize later.

\subsection{Material Characterization}

The experiments focus on high-temperature oxidation both in steam and air. Therefore, before and after each experiment the sample is weighed, measured and visually evaluated. The weighing is done with a scale accurate to the nearest $0.01 \mathrm{mg}$ and the measurement with a caliper rule with an accuracy of $0.01 \mathrm{~mm}$. As the deformation is not isotropic, the length is measured at 3 locations on the sample and the final length is the average of these three measurements. However, it may happen that the sample is considerably deformed so that dimensions cannot be measured. In this case, no measurement is made. The visual evaluation consists of noting any relevant remarks on the appearance of the sample (color of the oxide, location of the oxide layer etc.). Rings are then cut from the samples and further analyzed. The characterization includes also mettalography. Microhardness, mechanical testing or hydrogen concentration measurements will be carried out and published later.

\section{Results}

This section presents results of oxidation results with coated cladding first and then with reference uncoated material both in steam and air. Visual evaluation and results of mettalography are presented afterward.

\subsection{Weight GAin - CR-COATED ClAdDing}

The initial evaluation of the effectiveness of the protective coating with respect to oxidation, can be done by studying the mass gain. To evaluate and compare the results it is practical to deduce the oxidation kinetic parameters described by Eq. 11 [15]. For the purpose of the presented experiment, the weight gain is normalized by the surface of the specimen.

The oxidation kinetics can be first described by a parabolic law (Eq. 22 where the value of $n$ (oxidation exponent) is $2 . k_{1}$ is the rate of oxidation in $m g \cdot d m^{-2} \cdot m^{-1 / 2}$. It is important to note that the parameter $k_{1}$ is described by an Arrhenius law (Eq. 4) [16. This parameter depends on the temperature and activation energy, thus also on the type of material tested as well as the gas composition in the 
oxidizing environment. $K\left(m g . d m^{-2} \cdot m^{-1 / 2}\right)$ and $B(K)$ are experimental parameters. From Arrhenius law a linear relation between $\log (\mathrm{k})$ and $1 / \mathrm{T}$ is expected. The results are then fitted using this model to deduce these parameters. The values of $k_{1}$ as a function of temperature are shown in Figure 5. Table 2 summarizes experimental values of $\mathrm{K}$ and $\mathrm{B}$.

\begin{tabular}{lll}
\hline Alloy & K & B \\
\hline Cr-coated Optimized ZIRLO $^{\mathrm{TM}}$ & 11617231 & 18652 \\
\hline Uncoated Optimized ZIRLO $^{\mathrm{TM}}$ & 87137683 & 16259 \\
\hline
\end{tabular}

TABLE 2. K $\left(m g \cdot d m^{-2} \cdot m i n^{-1 / 2}\right)$ and B $(\mathrm{K})$ values for coated and uncoated cladding materials from Eq. 4 for air oxidation.

However, after a certain time, there is the oxidation kinetic change from the parabolic law described in previous paragraph. This moment is called breakaway and it is due to the fact that the oxide layer formed (protective oxide layer) at the beginning of the oxidation disrupts due to excessive stresses and reoxidation of the nitrides that formed. Thus, the oxidation strongly accelerates. After the transition, the $n$ value is equal to 1 leading to linear kinetics of oxidation Eq. 3. Combining both regions and equations (pre- and post-breakaway), the correlations can be derived and plotted (see Figure 3p.

$$
\begin{gathered}
\frac{d W G^{n}}{d t}=k(T) \\
W G(t) \sim k_{1}(T) \cdot t^{1 / 2} \\
W G(t)=k_{2}(T) \cdot t+W G_{0}-k_{2} \cdot t o \equiv k_{2}(T) \cdot t+C \\
k_{1}(T)=K e^{\frac{-E_{a}}{R T}} \equiv K e^{\frac{-B}{T}}
\end{gathered}
$$

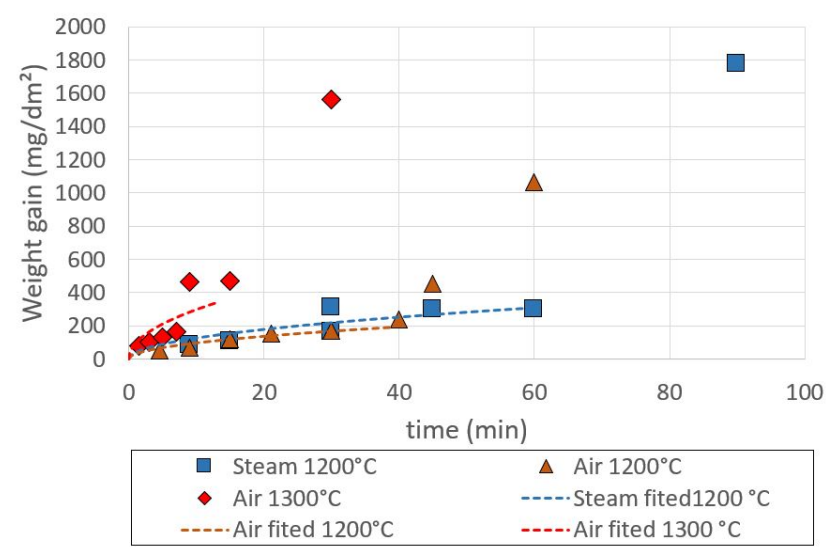

Figure 3. The results for oxidation with Cr-coated samples in steam at $1200{ }^{\circ} \mathrm{C}$ and air at 1200 and 1300 ${ }^{\circ} \mathrm{C}$. The fits show parabolic pre-breakaway part of the kinetics. Delayed breakaway point for oxidation in steam is visible.

\subsection{Weight Gain - UnCOATED Optimized ZIRLO ${ }^{\mathrm{TM}}$}

The same procedure was followed and measured weight gains of Optimized ZIRLO ${ }^{\mathrm{TM}}$ were fitted. The graph below shows the results for air oxidation with Optimized ZIRLO ${ }^{\mathrm{TM}}$ together with derived fits. It can be seen that there are two types of oxidation kinetics at $1000{ }^{\circ} \mathrm{C}$ with a transition between 20 and 30 minutes. On the other hand, there is no transition at $1200{ }^{\circ} \mathrm{C}$ when the accelerated oxidation is obvious from the beginning. It should be noted, that the values around $6000 \mathrm{mg} / \mathrm{dm}^{2}$ correspond to basically complete oxidation of the sample.

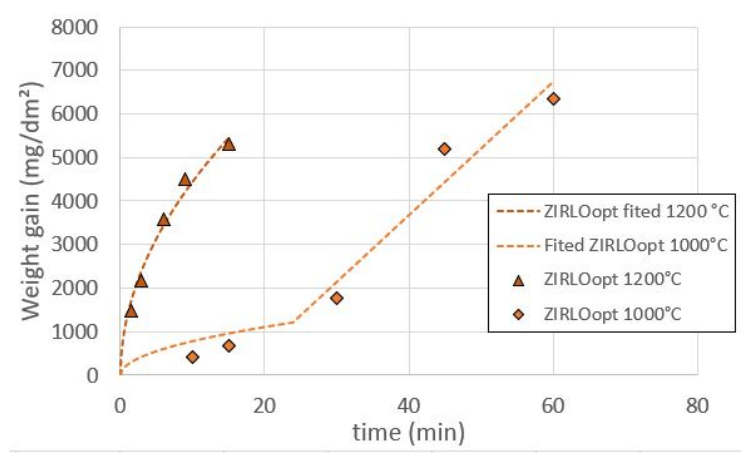

Figure 4. Weight gains for uncoated Optimized ZIRLO $^{\text {TM }}$ tested in air at 1000 and $1200{ }^{\circ} \mathrm{C}$. Pre- and post-breakaway regions are visible for $1000{ }^{\circ} \mathrm{C}$ but at there's not breakaway at $1200{ }^{\circ} \mathrm{C}$ since the kinetics is accelerated from the beginning.

To directly compare the oxidation of two materials (coated and uncoated), it is common to represent $k$ as a function of 10000/T to compare the oxidation kinetics of different materials (see Figure 5p. Since most of the experiments were performed in air, $k$ values are only shown for Optimized ZIRLOTM and Cr-coated Optimized ZIRLO ${ }^{\mathrm{TM}}$ in air. It can be seen that $k$ value of the coated samples is more than 30 times lower than for uncoated reference alloy. It should be noted, that more data points are needed in order to confirm this trend also for different temperatures.

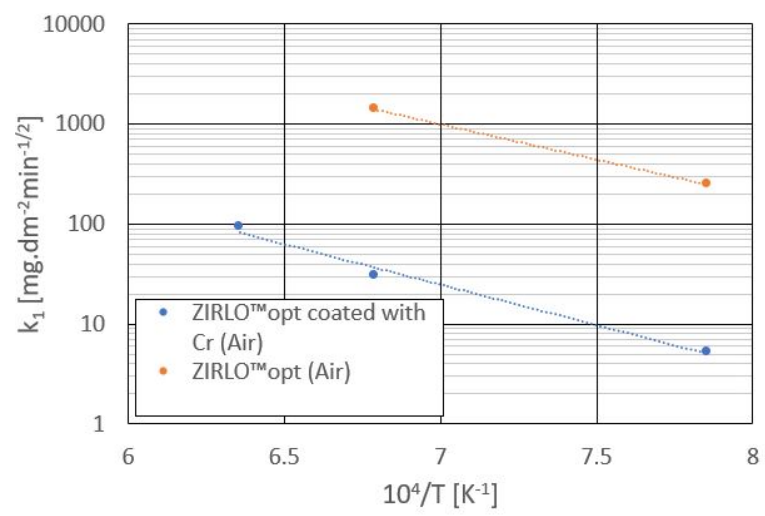

Figure 5. $k$ as a function of $10000 / \mathrm{T}$ for Cr PVD coated and uncoated Optimized ZIRLO ${ }^{\mathrm{TM}}$. 


\subsection{Visual EVALUATION}

Visual analysis makes it possible to qualitatively report on the condition of the sample after the experiment. In particular, it is obvious that coated samples are much more resistant to oxidation (Figure 6). It can be seen that the oxygen-rich white oxide layer forms for air oxidation and and sub-stoichiometric black oxide for steam oxidation. In addition, it is interesting to note that for coated samples, the chromium oxide layer only cracks around the drilled hole. The elongation trend of the samples can also be qualitatively observed from the pictures. The uncoated samples grow due to the oxidation creep when strongly oxidized. The changes in length are not considerable for coated samples. It is expected to see larger lenght changes at lower temperature due to phase transformations.

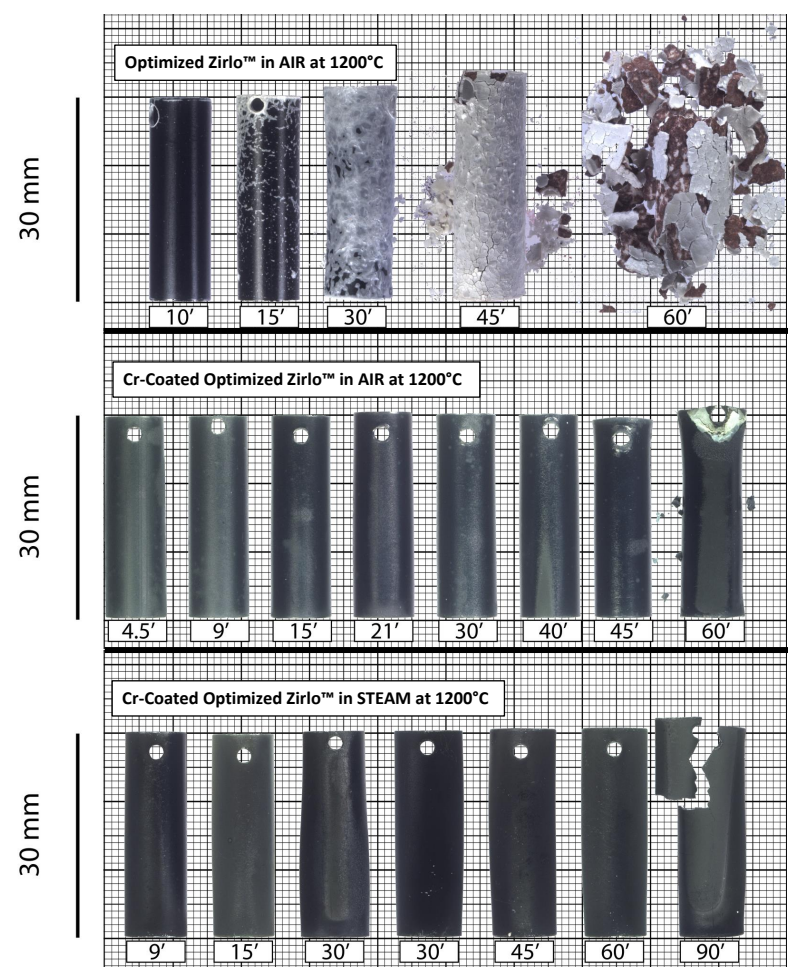

Figure 6. Photos of some samples after oxidation

It can be also noted that for the uncoated sample at $1000{ }^{\circ} \mathrm{C}$ after 60 minutes, the sample has fully oxidized and lost its mechanical integrity. However, during the experiment, the samples are kept in the furnace thanks to their hole. This sample must have fallen before it reached 60 minutes of exposure time, therefore the real oxidation time is lower.

\subsection{Microstructure}

The detailed microstructural analysis of all the samples is ongoing. It is, however, important to look at it to understand the oxidation phenomenon of these samples and the differences between coated and uncoated material. Thus, Figure 7 shows the microstructure of the Cr-coated Optimized ZIRLO ${ }^{\mathrm{TM}}$ after oxidation in air. To allow the comparison between coated and uncoated cladding material, microstructure of $\mathrm{Zr} 1 \mathrm{Nb}$ alloy is also shown for reference comparison.

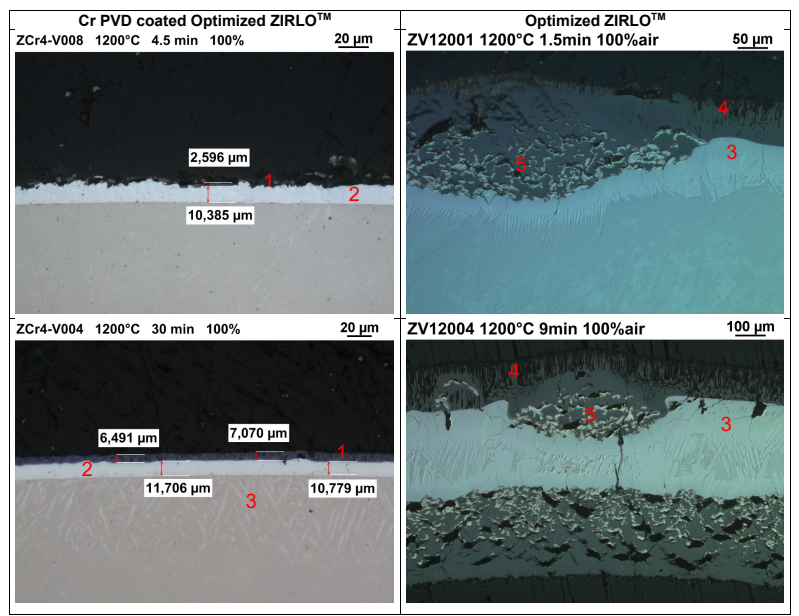

FiguRE 7. Microstructure after oxidation in air for $\mathrm{Cr}$ PVD coated sample oxidized for 4.5 and 30 minutes in comparison with uncoated sample oxidized for 1.5 and 9 minutes. (1. Outer $\mathrm{Cr}$ oxide 2. Remaining $\mathrm{Cr}$ metal layer 3. $\alpha-\mathrm{Zr}(\mathrm{O}) 4 . \mathrm{ZrO}_{2}$ 5. Porous $\left.\mathrm{ZrN}\right)$

During the oxidation in air for uncoated samples, a layer of $\mathrm{ZrO}_{2}$ (5) oxide is first formed. This layer is a protective one. But during oxidation this layer will eventually break which results in initiation of breakaway oxidation. From then on, the reaction accelerates. In addition, as oxygen is consumed by the oxidation reaction, the partial pressure of nitrogen increases, which leads to interaction of zirconium also with nitrogen to form nitrides (3). A porous $\mathrm{ZrN}$ and an oxide layer consisting of $\mathrm{ZrO}_{2}$ and $\mathrm{ZrN}$ are formed (6). It was shown that the formation of nitrides might lead to their re-oxidation and further oxidation acceleration.

Oxidation in air with coated samples is a little different. First a protective chromium oxide layer is formed (1). Due to diffusion of oxygen into the substrate, $\alpha$-Zirconium stabilized by oxygen is formed (4). As for the uncoated claddings, the protective layer can break, which leads to the acceleration of oxidation. As oxygen is consumed by the oxidation reaction, partial pressure of nitrogen increases, which causes reaction between nitrogen and the cladding and formation of thin $\mathrm{ZrN}$ layer (3).

Microstructure differences between coated and uncoated samples after oxidation in steam are shown in Figure 8 With Cr-coated sample, there is a chromium oxide layer and with uncoated one a zirconium oxide layer on the outermost surface. However, it may happen that after extremely long time of oxidation, steam penetrates the $\mathrm{Cr}$ coating and forms $\mathrm{Zr}$ oxide underneath which was observed for extremely long expositions. 


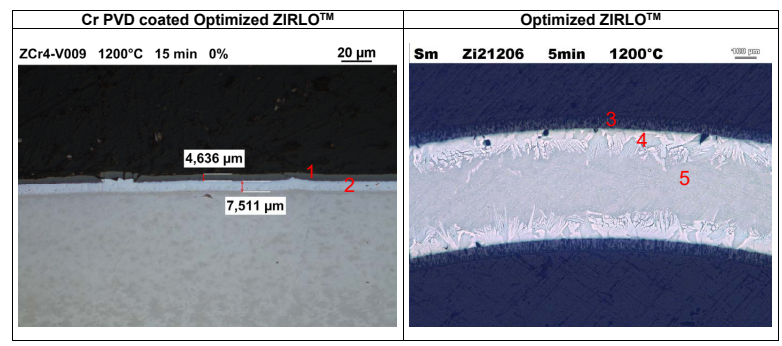

FiguRE 8. Microstructure after oxidation in steam for Cr PVD coated sample oxidized for 15 minutes in comparison with uncoated sample oxidized for 5 minutes. (1. Cr oxide 2. Cr metal layer 3. $\mathrm{ZrO}_{2} 4 . \alpha$ - $\mathrm{Zr}(\mathrm{O})$ 5. prior $\beta \mathrm{Zr}$

\section{Discussion}

Several points can be discussed based on the data measured. First, a breakaway was observed also for Cr-coated samples which has not been reported to date. However, for uncoated $\mathrm{Zr}$ alloys the transition can be seen only at lower temperatures which confirms strong protective effect of Cr PVD coating also in air containing environment. The visual analysis suggests that the oxide layer cracks only around the hole for hanging which causes the initiation of the transition of the coated samples. It is therefore possible that the chromium coating at this location does have different properties and lower adhesion due to complex geometry. So maybe by studying longer samples or different hanging designs, there might be no breakaway observed or it can be further delayed. It was also found the the ID coating is slightly thinner in comparison with OD and it can be seen that the breakaway initiates here. It is related to the characteristics of the PVD method used and chosen approach for elimination of uncoated areas of the samples.

Experimental kinetic parameters such as $K$ and $B$ can be deduced by studying weight gain. But for the moment there are not enough data to produce reliable correlation (especially for oxidation in the air of Optimized ZIRLO ${ }^{\mathrm{TM}}$ where only two temperature levels have been tested) but these parameters will be published in the near future. Similarly, the value of $n$ can be discussed because it may be slightly different from the theoretical value. To derive reliable correlation, it is necessary to fit two parameters so more data is needed to get a relevant result.

\section{CONCLUSiOn}

The study presented clearly shows that chromium PVD coated cladding samples have a better resistance to high temperature oxidation than uncoated ones in both steam and air for DBA as well as DEC conditions. It was confirmed by visual evaluation, microstructural analysis as well as derived oxidation parameters for both coated and uncoated materials. Moreover, the results show that oxidation in air is much faster than in steam for the considered temperature range including earlier occurrence of the breakaway point. These results further confirm that chromium PVD coating is a promising ATF cladding candidate from the perspective of chosen test conditions. It is necessary to continue the experiments to have more data to be able to answer the problems raised previously. It is therefore planned to continue the oxidation experiments in air but also in steam to test the samples in these two different high-temperature environments. The microstructure analysis of all the samples is ongoing as well as detailed characterization of the coating and substrate microstructure. Other samples with different coatings are also studied to compare them with the coating presented in this article. However, although the study of these new materials is motivated by accidents, it is important to note that this study focuses only on oxidation and that other parameters must be taken into account during such accidents, such as creep, hydrogen pickup, adhesion or cladding ballooning.

\section{LIST OF SYMBOLS}

$W G$ Weight gain $\left[\mathrm{mg} \mathrm{dm}^{-2}\right]$

$n$ Oxidation exponent, value is 1 or 2

$K$ Kinetic pre exponential factor $\left[\mathrm{mg} \mathrm{dm}^{-2} \mathrm{~min}^{-1 / 2}\right.$ ]

$E_{a} \quad$ Activation energy $\left[\mathrm{J} \mathrm{mol}^{-1}\right]$

$R$ Perfect gas constant $\left[\mathrm{J} \mathrm{mol}^{-1} \mathrm{~K}^{-1}\right]$

$T$ Temperature $[\mathrm{K}]$

$W G_{0}$ Weight gainbefore the break away $\left[\mathrm{mg} \mathrm{dm}^{-2}\right]$

$k_{1}$ Oxidation rate break away $\left[\mathrm{mg} \mathrm{dm}^{-2} \mathrm{~min}^{-1 / 2}\right]$

$k_{2}$ Oxidation rate after break away $\left[\mathrm{mg} \mathrm{dm}^{-2} \mathrm{~min}^{-1}\right.$ ]

$t_{0}$ Time where the break away happen [min]

$B=\frac{E_{a}}{R} \quad[\mathrm{~K}]$

$O D$ Outer diameter

$I D$ Inner diameter

$H D$ Hole diameter

$L \quad$ Length

\section{ACKNOWLEDGEMENTS}

The authors thank the Westinghouse Electric Company for providing Optimized ZIRLO ${ }^{\mathrm{TM}}$ substrate, UJP Praha zirconium group (J. Šustr, J. Kabátová, D. Rada, F. Manoch, A. Přibyl, and V. Vrtílková) for sample preparation, and post-experimental evaluation. Financial support of this research through ČEZ a.s. company is gratefully acknowledged. Also, this work was supported by the Ministry of Education, Youth and Sport of the Czech Republic, programme NPU1, project No LO1207, National Programme of Sustainability II Project LQ1603 (Research for SUSEN), IAEA CRP 21065 and Technology Agency of the Czech Republic grant No. TH02020477, TH02020691, CZ.2.16/3.1.00/21563.

\section{REFERENCES}

[1] N. OECD. State-of-the-Art Report on Light Water Reactor Accident-Tolerant Fuels, vol. 2018.

[2] IAEA. Accident tolerant fuel concepts for light water reactors 2016. [cit. 2018-01-25]. 

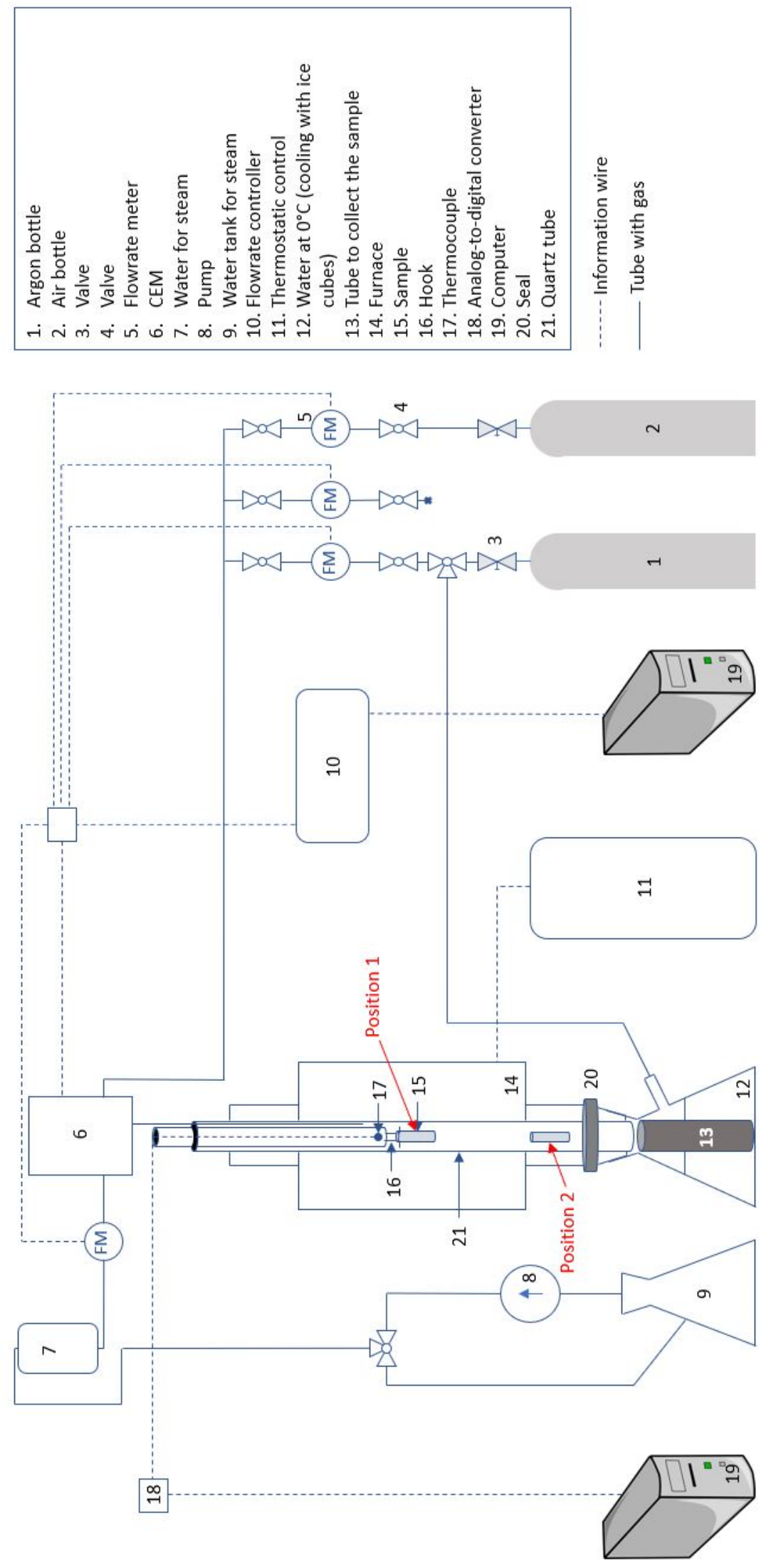

Figure 9. Schematics of the experiment procedure 
[3] A. Benjamin, D. McCloskey, D. Powers, S. Dupree. Spent fuel heatup following loss of water during storage. Nuclear Technology pp. 274-294, 1980.

[4] G. Pan, D. B. Mitchell, A. M. Garde1, et al. Advantages Gained by Optimized ZIRLO ${ }^{\mathrm{TM}}$ and AXIOM $^{\mathrm{TM}}$ PWR Cladding Materials. Top Fuel p. 1278, 2016.

[5] W. Luscher, K. Geelhood, I. Porter. Comparison between FRAPCON-4.0,FRAPTRAN-2.0, and MATPRO. U.S Department of energy, 2015.

[6] J. Krejčí, M. Ševeček, J. Kabátová, et al. Experimental Behavior of Chromium-based Coatings 2018:13.

[7] J. Krejčí, M. Ševeček, L. Cvrček, et al. Chromium and chromium nitride coated cladding for nuclear reactor fuel. In Proceedings of the 20th International Corrosion Congress, EUROCORR 201\%.

[8] S. Swann. Magnetron sputtering. Physics in Technology 19(2):67-75, 1988. DOI:10.1088/0305-4624/19/2/304.

[9] P. Kelly, R. Arnell. Magnetron sputtering: a review of recent developments and applications. Vacuum 56(3):159 - 172, 2000. DOI:10.1016/S0042-207X(99)00189-X

[10] M. Steinbrück, M. Böttcher. Air oxidation of Zircaloy-4, M5 ${ }^{\circledR}$ and ZIRLO ${ }^{\mathrm{TM}}$ cladding alloys at high temperatures. Journal of Nuclear Materials pp. 276 $285,2011$.
[11] Y. Yan, T. Burtseva, M. Billone. High-temperature steam-oxidation behavior of zr-1nb cladding alloy e110. Journal of Nuclear Materials 393(3):433 - 448, 2009. DOI:10.1016/j.jnucmat.2009.06.029

[12] M. Steinbrück, N. Vér, M. Große. Oxidation of Advanced Zirconium Cladding Alloys in Steam at Temperatures in the Range of $600-1200{ }^{\circ} \mathrm{C}$. Oxidation of Metals 76(3):215-232, 2011. DOI:10.1007/s11085-011-9249-3.

[13] S. Zinkle, K. Terrani, J. Gehin, et al. Accident tolerant fuels for lwrs: A perspective. Journal of Nuclear Materials 448(1):374 - 379, 2014. DOI:10.1016/j.jnucmat.2013.12.005

[14] M. Steinbrück, U. Stegmaier, T. Ziegler. Prototypical experiments on air oxidation of Zircaloy-4 at high temperatures, vol. 7257. FZKA, 2007.

[15] M. Stempniewicz. Air oxidation of Zircaloy,Part 1 Review of correlations. Nuclear Engineering and Design 2016.

[16] G.Schanz, B.Adroguer, A.Volchek. Advanced treatment of zircaloy cladding hight temperature oxidation in sever accident code calculations. Nuclear Engineering and Design pp. 75-84, 2004. 